Historic, Archive Document

Do not assume content reflects current scientific knowledge, policies, or practices. 

Reserve aQR495

.G74B34 1997

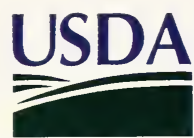

ited States D partpent of Agriculture

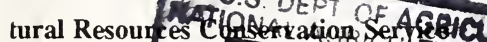

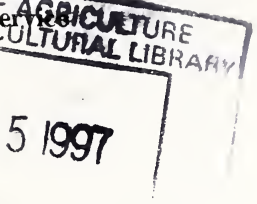

BADLANDS Ecotype Little Bluestem

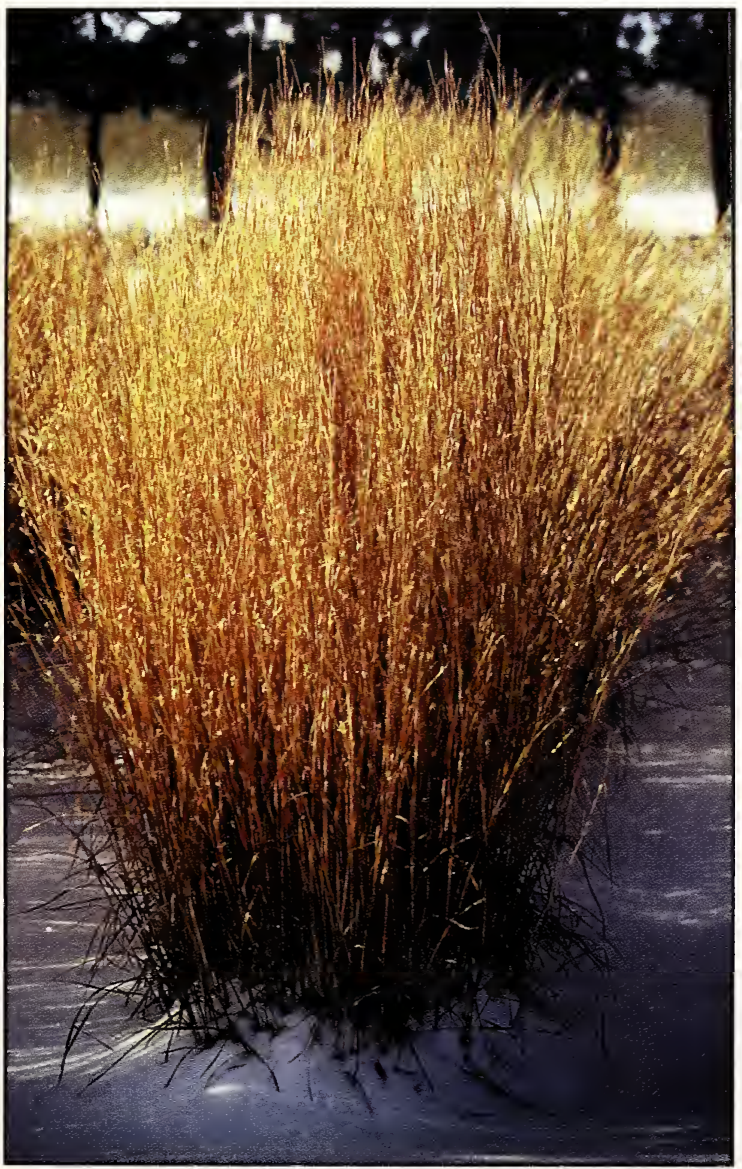




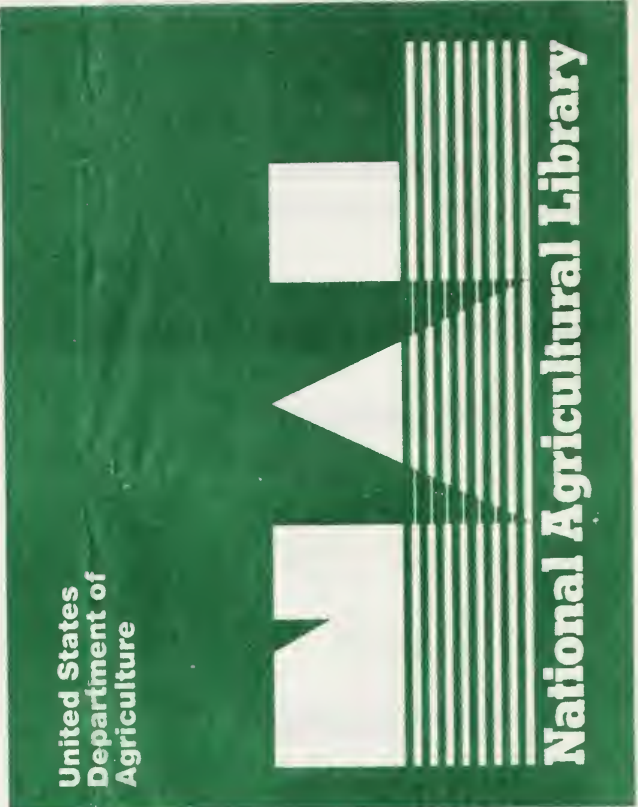

- Deep, fibrous root system

- Basal portions of stems are flattened

- Leaves are slightly folded

- Leaves become reddish brown at maturity, red in fall/winter

- Mature seed heads become fluffy, white

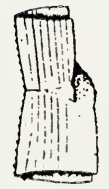

Flattened leaf sheath

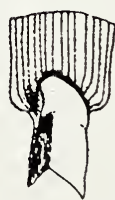

Papery ligule 


\section{Projected Area of Adaptation}

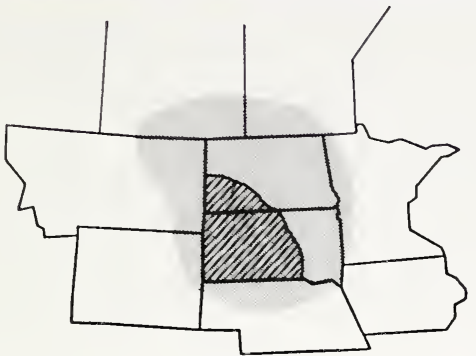

Collection area of Badlands ecotype (lined) and projected area of adaptation

\section{Badlands Ecotype Features}

- The source population is a composite of plants from 68 different sites, including the Badlands region of North Dakota and South Dakota

- A broad, genetic base with plants originating from many different range sites, but primarily shallow, thin upland, sandy, and silty

- Improved plant vigor, seed production, and disease resistance

- Variation in plant size, leaf width, and color

- Plant color varies form light to dark green with occasional blue plants

- Phenology may vary up to two weeks within the population

- First seed matures generally in late August at Bismarck, ND

- Approximately 4 weeks earlier in maturity compared to Blaze and Camper

- Original area of collections includes USDA Plant Hardiness Zones 2, 3, \& 4 


\section{Establishment}

- Seed from mid-May to mid-June

- Shallow seeding depth of .25 to .5 inches is critical

- Plant through fluffy seedbox with grass drill unless the seed is debearded

- Plant at a seeding rate of 25 to 30 pure live seeds (PLS) per $\mathrm{ft}^{2}$ if planted alone 14.2 to $5.0 \mathrm{PLS} \mathrm{lb} / \mathrm{ac}$ ); generally little bluestem is one component of a range mix, so rate varies depending on percent desired in the stand

- Number of seeds/pound averages 270,000; debearded seed will vary from this amount

- Accent plants for landscaping are generally spaced at 1 to 2 feet

\section{Management}

- Proper grazing would include not removing more than half of the new growth during the growing season

- Quality declines with growth stage, dropping rapidly as the plant matures and sets seed

- Prescribed burning in late winter or spring will increase seed production and improve forage quality

- Without proper use or burning, little bluestem can form dead centers

- Plant crowns may suffer severe damage when burned during dry conditions 



\section{Seed Production}

- Seed harvest can be accomplished by combining or stripping

- Because of the light, fluffy seed, air should be reduced or closed

- Variable seed maturity, even on the same plant, is common

- Seed strippers can be used after seeds have reached the "full-fluff" stage, but before heavy shattering occurs

- Annual seed yields can be extremely variable

- Clean seed yields at the Bismarck Plant Materials Center have averaged 100 to $200 \mathrm{lb} / \mathrm{ac}$ with irrigation and 42-inch row spacing

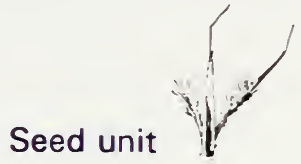

\section{Seed Availability}

Generation 2 seed, equivalent to foundation seed, is available for seed increase from the USDA, NRCS Plant Materials Center, Bismarck, North Dakota. Certified seed is available from various commercial vendors. Contact your local USDA, NRCS Field Office or the Bismarck Plant Materials Center for a list of vendors.

\section{Origin}

Selected plants comprising Badlands little bluestem originated from 68 different sites in southwestern North Dakota and western and central South Dakota. The diverse genetic plant material was collected vegetatively on 10 different range sites. 